\title{
George H. Born
}

George H. Born received the Ph. D. in Aerospace Engineering from the University of Texas at Austin in 1968. For over 40 years his research has contributed to the fields of precision orbit determination, interplanetary mission design, satellite navigation, and satellite oceanography. Following graduation, he worked on the Apollo Program as a civil servant at the Manned Spacecraft Center for two years. In 1970 he joined the Jet Propulsion Laboratory where he served on the navigation team of Mariner 9, was the Technical Group Supervisor in charge of the Mars orbit determination for the Viking missions, and served as the Geophysical Evaluation Manager for the Seasat Project. The Seasat spacecraft, which flew in 1978, carried the first suite of microwave instruments for monitoring the global oceans. As Geophysical Evaluation Manager, he was in charge of the efforts to demonstrate that the instrument package containing a radar altimeter, windfield scatterometer, synthetic aperture radar, scanning multichannel microwave radiometer, and a visual and infrared radiometer, met all specifications for measuring geophysical parameters over the ocean. These included sea surface topography, sea surface temperature, atmospheric water vapor, and ocean surface imaging. This body of work has led him to be selected as a member of the National Academy of Engineering, become a Fellow of the American Astronautical Society, receive the American Astronautical Society Dirk Brouwer Award, as well as receive the AIAA Mechanics and Control of Flight Award.

In 1985, he joined the Aerospace Engineering Sciences Department at the University of Colorado as a professor, and founded the Colorado Center for Astrodynamics Research (CCAR), which he directs. CCAR, which is enjoying its 25 th anniversary this year, is a multidisciplinary center involving faculty, staff, and students from the Department of Aerospace Engineering Sciences. Its research program emphasizes astrodynamics, space mission design and satellite navigation, GPS technology development and applications, meteorology, oceanography, geodesy, and terrestrial vegetation studies with in situ and remote sensing data. 